Preprints of the

Max Planck Institute for

Research on Collective Goods

Bonn 2008/17

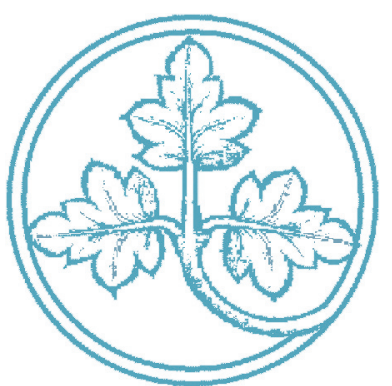

Size, Spillovers and

Soft Budget Constraints

Ernesto Crivelli / Klaas Staal

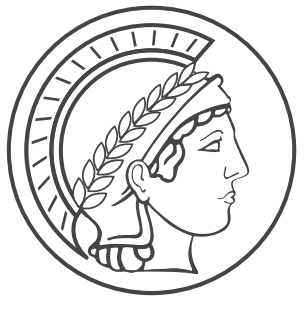

MAX PLANCK SOCIETY 


\title{
Size, Spillovers and Soft Budget Constraints
}

\author{
Ernesto Crivelli / Klaas Staal
}

April 2008 


\title{
Size, Spillovers and Soft Budget
}

\section{Constraints*}

\author{
Ernesto Crivelli ${ }^{\dagger} \quad$ Klaas Staal ${ }^{\ddagger}$
}

\begin{abstract}
There is much evidence against the so-called "too big to fail" hypothesis in the case of bailouts to subnational governments. We look at a model where districts of different size provide local public goods with positive spillovers. Matching grants of a central government can induce socially-efficient provision, but districts can still exploit the intervening central government by inducing direct financing. We show that the ability and willingness of a district to induce a bailout and district size are negatively correlated. We also discuss the effect economies of scale in local public goods provision has on the bailout policies and argue that these policies can be subgame perfect equilibrium strategies.
\end{abstract}

Key Words: bailouts, soft-budget constraints, district size, spillovers

JEL Codes: H4, H7, R1

*We would like to thank Jürgen von Hagen, Patrick Beschorner, Christoph Engel and participants of the SFB Workshop (Würzburg), the SFB Tagung (Frauenchiemsee), the Association of Public Economic Theory Meeting (Hanoi), the CESifo-IFIR Conference (Lexington), the INFER Annual Conference (Cork), the IIPF Conference (Warwick), the World Meeting of the Public Choice Society (Amsterdam) and seminars at the University of Bonn and Center for European Integration Studies (Bonn). Financial support from the Deutsche Forschungsgemeinschaft through SFB/TR 15 and the Bonn Graduate School of Economics is gratefully acknowledged.

${ }^{\dagger}$ Max Planck Institute for Research on Collective Goods, Kurt-Schumacher-Str. 10, 53113 Bonn, Germany. Email: crivelli@coll.mpg.de

†University of Bonn, Lennéstr. 37, 53113 Bonn, Germany. Email: kstaal@uni-bonn.de 


\section{Introduction}

There is much evidence supporting the conjecture that the occurrence of bailouts to subnational governments in general contradicts the so-called "too big to fail" hypothesis. A first example is that, based on the constitutional principle of uniformity of living conditions throughout the nation, the German Constitutional Court supported in 1992 the bailout claims of the two smallest state governments in terms of population, Bremen and Saarland. The German Constitutional Court forced the federal government to give bailout transfers to ensure the basic supply of local public services in these states (Seitz, 1999). At the beginning of the 1990s, the health system was facing a deficit of about $15 \%$ in small regions in Italy ${ }^{1}$. Following the constitutional principle that guarantees citizens access to the same quality of services, the central government stepped in and covered the deficits thus incurred to prevent health care in these regions break down (von Hagen et al, 2000). In Sweden, the central government was empowered by law during the period 1974-1992, to provide discretionary transfers to support municipalities in financial distress ${ }^{2}$. Econometric evidence for this period (Dahlberg and Pettersson, 2003), shows that population size has a significant negative association with realized bailouts. Also in Latin America, a number of recent experiences in Argentina, Colombia and Costa Rica contradict the "too big to fail" hypothesis. In Argentina for example, the central government has often used extraordinary resources to face fiscal and financial crises at provincial

\footnotetext{
${ }^{1}$ In 1992 , ordinary regions spent $71 \%$ of their total resources on health services. Almost $96 \%$ of their revenues came from central government (matching) grants. (von Hagen et al, 2000).

${ }^{2}$ This relief program was not part of a regular intergovernmental transfer scheme (von Hagen et $\mathrm{al}, 2000)$.
} 
level since the return of democracy in 1983. In general, they took place in jurisdictions that are among the smallest in terms of population ${ }^{3}$ (Nicollini et al, 2002). ${ }^{4}$ Two aspects of these episodes motivate the analysis of this paper: First, the risk of underprovision of public goods by subnational governments is an important reason for central governments to bail out subnational governments. Second, subnational governments of small districts are more likely to induce and get a bailout from the central government.

This paper investigates the ability and willingness of local governments to induce a central government to directly finance the provision of the local public goods, i.e. to induce bailouts ${ }^{5}$. We develop a two-tier hierarchy model with the central government at the top and several districts of different size at the bottom. Districts provide local public goods ${ }^{6}$ and we assume that there are economies of scale and (positive) externalities in the provision of public goods. As in for example Alesina

\footnotetext{
${ }^{3}$ Bailout episodes during the 1990s include the provinces of Jujuy, La Rioja, Tucuman, Catamarca, Corrientes, Santiago del Estero and Rio Negro, that are the smallest in terms of population if we exclude the extremely sparsely populated and oil producing provinces in Patagonia in the south of the country. Moreover, these provinces together represent less than $13 \%$ of the total population and less that $10 \%$ of national GDP.

${ }^{4}$ It is important to point out that we are not interested in episodes of generalized bailouts like, for example, the rescue operation implemented by the federal government in Mexico early after the financial crisis in December 1994 which included extraordinary transfers to all state governments. Another example is Brazil, where the federal government assumed all state and municipal debt in 1993 and 1997 (Dillinger and Webb, 1998). Moreover, note that the recent fiscal crisis faced by the city of Philadelphia in the US in 1990 cannot be considered a case of bailout since the fiscal cost of the crisis was mainly internalized by its residents living with reduced public services, additional sales tax and city workers facing a wage freeze and a reduction in employee benefits (Inman 1995).

${ }^{5}$ Note that bailouts are usually provided to cope with high public indebtedness. Although there is no debt in our model, the implication is the same since coping with high public debt could imply that jurisdictions have to cut expenditures drastically, resulting in severe deteriorations of the supply of public goods.

${ }^{6}$ Throughout this paper we write public goods, though, strictly speaking, we mean publicly provided goods.
} 
and Spolaore (1997), economies of scale are modelled with a fixed cost associated with public goods' provision. Further, we assume that there are (positive) externalities in the provision of public goods. This spillover effect is modelled in a similar way as Besley and Coate (2003), that is, public goods provided in a district do not only benefit individuals in this particular district, but also entail a positive externality for individuals in other districts.

The paper analyzes whether and when the central government is willing to make an extraordinary transfer (bailout) to a district, which decides to underprovide local public goods ${ }^{7}$. We argue that district size plays an important role in the bailout policy of central and local governments, as well as in the occurrence of bailouts in equilibrium. It turns out that the willingness of the central government to provide a bailout to a certain district depends negatively on the size of this district: the larger the district, the more costly a bailout is for the individuals outside this district. The central government's bailout policy, however, does not fully characterize the occurrence of bailouts, since it is not obvious whether districts are indeed willing to induce bailouts.

In general, bailouts are attractive for individuals in a district if the amount of public goods provided under the central government's bailout policy is big enough. It turns out that small districts get a larger amount of public goods per capita under the bailout policy. In agreement with the empirical evidence, individuals in small districts are, therefore, more likely to induce and get a bailout. Furthermore, we argue that these bailout policies can be the strategies in a subgame-perfect Nash

\footnotetext{
${ }^{7}$ This decision making process is similar to the one studied by Caplan et al. (2000) when they look at a federation with centralized leadership and immobile residents.
} 
equilibrium.

This line of research drawing the attention to size effects when analyzing problems of soft budget constraints was pioneered by Wildasin (1997), who develops a model where externalities in the provision of local public goods explain the allocation of bailouts among districts ${ }^{8}$. In clear contrast to our resuts, Wildasin finds that the size of a district positively affects its likelihood of demand and obtaining a bailout. As we argue above, this does not seem to find support in recent episodes of bailouts to subnational governments. Furthermore, this paper differs from Wildasin's by analyzing explicitly how bailouts can occur in equilibrium. Additionally, in Wildasin's model, bailouts are financed by reducing the availability of public goods provided by the center. Our analysis, in contrast, assumes that bailouts are financed by increasing federal taxes. Finally, we assume that there are economies of scale in the provision of public goods.

The remainder of the paper is organized as follows. In Section 2 we introduce the model and define the non-cooperative and efficient outcomes under hard budget constraint. The paper starts with looking at the non-cooperative outcome. Individuals choose the amount of public goods to be provided in their district. It follows that districts only provide local public goods when district size is large enough relatively to the economies of scale effect in local public good provision. A common finding in this form of decision making is, however, that the spillover effect is not taken

\footnotetext{
${ }^{8}$ Recent literature on soft budget constraints and bailouts also include: Qian and Roland (1998), Inman (2001), Goodspeed (2002) and Sanguinetti and Tommasi (2002). See also Kornai (1986), who introduces the discussion on soft budget constraints in the study of state-owned enterprises, Dewatripont and Maskin (1995) for soft budget constraints in a credit model and Maskin (1999) for a survey.
} 
into account and, therefore, underprovision of local public goods occur. We further characterize the optimal level of local public goods provision and define a system of matching grants implemented by a central government that can be used to achieve an efficient outcome without completely centralizing decision making. In line with the literature, we find that the (strictly positive) amount of public goods provided in a non-cooperative Nash equilibrium is lower than the level in an efficient outcome. We find also that in less cases than socially optimal, local public goods are provided when district size is small relative to the economies of scale in local public goods provision.

The paper then shifts attention to the issue of soft budget constraints. In Section 3 , it analyzes whether and when the central government is willing to make an extraordinary transfer (bailout) to a district that decides to underprovide local public goods $^{9}$. It turns out that the willingness of the central government to provide a bailout depends negatively on the size of this district. In addition to that, we argue that the central government's bailout policy does not fully characterize the occurrence of bailouts. Since it is costly for individuals to induce a bailout (in case of a bailout there will be less local public goods in their districts than they are willing to pay for), the conditions under which local governments indeed choose to induce such a bailout are subsequently identified. In agreement with the empirical evidence, as district size decreases, the bailout becomes in general more attractive for a district, and the willingness of a local government to induce a bailout increases. In Section 4, we argue that these bailout policies can be the strategies in a subgame-perfect Nash

\footnotetext{
${ }^{9}$ This decision making process is similar to the one studied by Caplan et al. (2000) when they look at a federation with centralized leadership and immobile residents.
} 
equilibrium. Even though the central government could choose to change the optimal system of matching grants to avoid costly bailouts, it turns out that this is not enough to avoid bailouts in all cases. Finally, Section 5 summarizes and concludes.

\section{The Model}

Suppose that a country is divided in $\mathcal{N}$ districts of different size. The country has a population of $N$ individuals and each district $i$ has a population of $n_{i}$, where $n_{i}<N / 2$ for all districts. Each individual has an endowment $y$ and there are two types of goods in the economy, a private good $x$ and a public good $g$. To simplify notation and to show that the results do not depend on heterogeneity among individuals, we assume that all individuals have identical preferences and endowments. We assume that an individual's payoff is quasilinear in the endowment and that the utility function is additively separable.

We assume that there are economies of scale in public good provision. This feature is modelled with a fixed cost $F$ for providing public goods, regardless of the size of the district. There is also a variable cost that depends on the exact amount of public goods that individuals want to provide. A district $i$ provides per capita an amount $g_{i}$ of the local public goods and each individual in district $i$ pays a lump-sum district tax $t_{i}$ to finance public good provision in district $i$. If a district provides an amount

$g_{i}$ of the public good then individuals in this district will get a benefit $v\left(g_{i}\right)$ from these public goods. We assume that $v($.$) is strictly concave, that v^{\prime}()>$.0 and that $v(0)=0$. An individual, however, does not only get a payoff from the public good 
in his own district but also from the public goods in all other districts. The degree of this (positive) spillover effect is denoted by $\kappa, 0<\kappa<1$, so that an individual in district $i$ gets a benefit $\kappa v\left(g_{j}\right)$ of the public goods provided in district $j,(i \neq j){ }^{10}$.

To illustrate this consider two examples, health care and education. An individual in the first place benefits from vaccinations and basic literacy in his own district. There are, however, diminishing returns since an individual benefits less from say plastic surgery or some forms of university education. In the second place an individual also indirectly benefits from these goods provided in other districts. since an individual may sometimes interact with individuals from other districts, and the provision of public goods there make these interactions more beneficial. In these cases, the economies of scale in public good provision, represented by the fixed costs, is for example a single bureaucracy that is responsible for health care and education in each district. The variable costs then represents how much health care or education per individual is available.

Thus, the utility of an individual in district $i$ is

$$
v\left(g_{i}\right)+\sum_{j \neq i} \kappa v\left(g_{j}\right)+y-t_{i}
$$

The costs of providing public goods differ per district and its variation is captured by the strictly positive parameter $p_{i}$. The value of $p_{i}$ is known to the individuals in district $i$ but unknown to the central government. Since districts have balanced

\footnotetext{
${ }^{10}$ The main argument behind the "too big to fail" hypothesis is that spillovers are important and increasing in district size. This is for example the case when the spillover effect is proportional to district size, so that an individual in district $i$ gets a benefit $\kappa n_{j} v\left(g_{j}\right)$ of the public goods provided in district $j$. In an Appendix we show that the main results of our paper are robust to this alternative specification.
} 
budgets, tax rates $t_{i}$ are given by

$$
t_{i}= \begin{cases}\frac{F}{n_{i}}+p_{i} g_{i} & \text { if } g_{i}>0 \\ 0 & \text { if } g_{i}=0\end{cases}
$$

We assume that all individuals in a district can choose the amount of public goods provided in their district. Since the individuals within a district are identical, however, we only have to look at the preferences of a single individual as these preferences prevail for all individuals in the same district. The level of public goods provided in a district $i$ is thus determined by the following maximization problem

$$
\max _{g_{i}} v\left(g_{i}\right)+\sum_{j \neq i} \kappa v\left(g_{j}\right)+y-t_{i}
$$

where $t_{i}$ is given by (2). The non-cooperative Nash equilibrium outcome is characterized by the following first-order condition of maximization problem (3): ${ }^{11}$

$$
\begin{cases}v^{\prime}\left(g_{i}\right)=p_{i} & \text { if } v\left(g_{i}\right)>\frac{F}{n_{i}}+p_{i} g_{i} \\ g_{i}=0 & \text { otherwise }\end{cases}
$$

From the first-order condition (4) it follows that districts only provide local public goods when district size is large enough compared to the economies of scale effect in the provision of local public goods.

It is a common finding that in the form of decision making described above, the

\footnotetext{
${ }^{11}$ In this and in subsequent maximization problems the strict concavity of $v($.$) implies that the$ first order conditions are sufficient. Moreover, the strict concavity implies that the solutions are unique.
} 
spillover effect is not taken into account and, therefore, underprovision of local public goods occurs ${ }^{12}$. A system of grants, however, can be used to achieve an efficient Nash equilibrium without completely centralizing decision making. We assume that such a system is implemented by a central government and that, to finance this system, individuals pay a national lump-sum tax $T$. In order to characterize such an equilibrium, we first determine the optimal levels of local public good provision as a benchmark for normative evaluation of equilibrium outcomes. Then we characterize a system of matching grants that induces local governments to provide these optimal levels of local public goods.

Since in this model the payoffs are quasilinear in the endowment, for efficiency it suffices to focus on an outcome in which all individuals pay the same tax level. The objective is to maximize the equally weighed sum of all individual utilities. The maximization problem for determining $g_{i}$ can therefore be written as

$$
\max _{g_{i}} n_{i} v\left(g_{i}\right)+\sum_{j \neq i} n_{j} \kappa v\left(g_{i}\right)+N y-N T
$$

and since the budget is balanced

$$
T=\sum_{j \mid g_{j}>0} \frac{F+n_{j} p_{j} g_{j}}{N}
$$

We define $\hat{g}_{i}$ to be the socially optimal or efficient per-capita amount of public goods

\footnotetext{
${ }^{12}$ See, for example, Besley and Coate (2003) who work with a model in which individuals differ in their preferences over public good provision. Feidler and Staal (2007) show that district size can be seen as a proxy for this heterogeneity in preferences.
} 
if $\hat{g}_{i}$ satisfies the following first-order condition of (5):

$$
\begin{cases}v^{\prime}\left(\hat{g}_{i}\right)=\frac{n_{i} p_{i}}{n_{i}+\left(N-n_{i}\right) \kappa} & \text { if } \begin{array}{l}
v\left(\hat{g}_{i}\right)+\frac{1}{n_{i}} \sum_{j \neq i} n_{j} \kappa v\left(\hat{g}_{i}\right)> \\
\hat{g}_{i}+p_{i} \hat{g}_{i}
\end{array} \\
\hat{g}_{i}=0 & \text { otherwise }\end{cases}
$$

From the first-order condition (7) it follows that it is only efficient to provide local public goods when district size is large enough compared to the economies of scale in local public good provision. A comparison of the first-order conditions (7) with (4) yields that there is indeed underprovision of public goods. Firstly, the strictly positive levels of public goods in a non-cooperative Nash equilibrium are lower than the level in an efficient outcome. Furthermore, the minimum district size for providing a positive amount of the public good is larger than in the efficient outcome.

Below, we consider a system consisting of matching (or conditional) grants. The timing is now as follows.

1. The central government chooses a system of matching grants.

2. The local governments observe the system of matching grants and choose the amounts of local public goods that will be provided.

Let $m_{i}$ denote the share of total spending the local government of district $i$ for which the local government is reimbursed. This reimbursement is chosen such that the marginal incentives to provide local public goods are efficient. Again, districts have balanced budgets and therefore tax rates previously given by expression (2) are now 
given by

$$
t_{i}= \begin{cases}\left(\frac{F}{n_{i}}+p_{i} g_{i}\right)\left(1-m_{i}\right) & \text { if } g_{i}>0 \\ 0 & \text { if } g_{i}=0\end{cases}
$$

and the national tax rate is given by

$$
T=\frac{\sum_{j \mid g_{j}>0}\left(F+p_{j} n_{j} g_{j}\right) m_{j}}{N}
$$

The level of public goods provided in a district $i$ is then implicitly given by maximization problem (10) with tax rates $t_{i}$ and $T$ given by expressions (8) and (9), respectively.

$$
\max _{g_{i}} v\left(g_{i}\right)+\sum_{j \neq i} \kappa v\left(g_{j}\right)+y-t_{i}-T
$$

The first-order condition of this maximization problem is given by

$$
\begin{cases}v^{\prime}\left(g_{i}\right)=p_{i}\left(1-m_{i}\right)+\frac{n_{i} p_{i} m_{i}}{N} & \text { if } \begin{array}{l}
v\left(g_{i}\right)> \\
\left(\frac{F}{n_{i}}+p_{i} g_{i}\right)\left(1-m_{i}\right)+\frac{\left(F+n_{i} p_{i} g_{i}\right) m_{i}}{N} \\
g_{i}=0
\end{array} \\
\text { otherwise }\end{cases}
$$

Note that the districts provide a positive amount of public goods only if the benefit of doing this outweights the cost, what is represented by the local tax and the portion of federal tax paid by the individuals in the district to finance the matching grants. From (7) and (11) it follows that the marginal incentives to provide local public goods is optimal with the following conditional transfers $\hat{m}_{i}$

$$
\hat{m}_{i}=\frac{N \kappa}{n_{i}+\left(N-n_{i}\right) \kappa}
$$


The marginal incentives to provide public goods are now efficient, moreover, a comparison of the conditions in (7) and (11) with $m_{i}=\hat{m}_{i}$ reveals that the decision whether to provide public goods is now also efficient, that is $g_{i}=\hat{g}_{i}$ for all $i$. Another feature of the transfer scheme characterized by (12) is that the transfers $\hat{m}_{i}$ do not depend on the values of the $p_{i}$ 's. Furthermore, when individuals choose $g_{i}$ given matching grants $\hat{m}_{i}$ then $\hat{g}_{i}$ constitutes the unique Nash equilibrium outcome. The above transfer scheme would, therefore, be the outcome that a benevolent, socialwelfare maximizing, national government would choose. It is, however, also the scheme individuals would choose in case they would vote ex-ante, without knowing their district sizes, over a transfer scheme. Although majority voting, with knowledge of district sizes, might lead to a different transfer scheme, the result presented in the next section is stronger with the social-welfare maximizing transfer scheme: Even with such a scheme, the efficient outcome will not always be obtained when there is a soft budget constraint.

\section{The soft budget constraint}

In Section 2, we show that the first-best outcome can be reached with matching transfers. The motivation behind a system of matching grants is given by the benefits individuals outside a district get from the local public goods provided in this district. This motivation also creates, however, another possibility. When a district does not provide any local public goods at all, the central government could make a transfer to this district so that at least some public goods are provided in this district so that 
people outside the district have the benefits from the spillovers. This motivation seems to be an essential feature of bailouts of central to local governments. The bailout policy is thus carried out in the interest of those individuals that are not located in the district inducing a bailout. This policy leads to the same bailouts as with majority voting, that is when individuals vote over pairwise comparisons of bailout levels.

We focus on the decision of the individuals in a single district $i$ and in the analysis we assume that all other districts choose the positive levels given in Section 2. Even when the central government is willing to give a district a bailout, the choice of the individuals whether to induce such a bailout still depends on the increase in the central tax level necessary to finance the bailout, and the amount of local public goods provided in the district under a bailout. The decision on the bailout is taken after the decisions on the amount of local public goods are made by the districts. The timing is thus:

1. The central government chooses a system of matching grants.

2. The local governments observe the system of matching grants, choose the amounts of local public goods that will be provided and choose whether to induce a bailout.

3. The central government, observing the choices made by local governments, decides on bailouts induced by local governments.

In the following analysis we look at this game recursively, that is first at the central government's bailout policy and then at the decision over local public goods provision 
in district $i$. We assume that bailouts are costly, since the central government has to put effort in finding out what the local cost parameter $p_{i}$ is, and additional public employees are necessary to survey the bailout. The costs of these efforts are denoted by $c_{B O}$ and do not depend on district size. As already done for the system of matching grants, majority voting arguments are also given for the central and local governments' policies. Finally, we use $\underline{m_{i}}$ to denote the size of the bailout to district $i$ and $T_{B O}$ for the change in the tax rate of the central government needed to finance the bailout.

\subsection{Central government bailout policy}

In this section we look at the reaction of the central government when the individuals in a district choose a $g_{i}$ and thus a $t_{i}$ such that $g_{i}<\hat{g}_{i}$. Now the central government can intervene in district $i$ 's provision of local public goods $g_{i}$ by making a lump-sum grant such that, per capita, an amount of local public goods in district $i$ of $g_{i}+\underline{m_{i}}$ is

provided. We do not drop the assumption that budgets are balanced, so to finance this transfer the central tax level is increased by $n_{i} p_{i} \underline{m_{i}} / N$. Finally, since bailouts are costly, the central tax rate additionally increases by $c_{B O} / N$ for each bailout.

Given these assumptions, the central government maximizes the payoff of an individual located outside the district that might get a bailout, and this optimization problem can be written as

$$
\max _{\underline{m_{i}}} \kappa v\left(g_{i}+\underline{m_{i}}\right)-T_{B O}
$$


where $T_{B O}$ denotes the raise in the central tax rate due to the bailout and is given by

$$
T_{B O}= \begin{cases}\frac{F+n_{i} p_{i} g_{i}+c_{B O}+n_{i} p_{i} \underline{m_{i}-t_{i} n_{i}}}{N} & \text { if } \underline{m_{i}}>0 \\ \frac{c_{B O}}{N} & \text { if } \underline{m_{i}}=0\end{cases}
$$

The first-order condition of this maximization problem is given by

$$
\begin{cases}\kappa v^{\prime}\left(g_{i}+\underline{m_{i}}\right)=\frac{n_{i} p_{i}}{N} & \text { if } \begin{array}{l}
\kappa v^{\prime}\left(g_{i}\right)>\frac{n_{i} p_{i}}{N} \text { and } \\
\kappa v\left(g_{i}+\underline{m_{i}}\right)>\frac{F+n_{i} p_{i} g_{i}+c_{B O}+n_{i} p_{i} \underline{m_{i}}-t_{i} n_{i}}{N} \\
\underline{m_{i}=0}
\end{array} \quad \text { otherwise }\end{cases}
$$

A comparison of conditions (15) and (7) reveals that the amount of public goods provided under the bailout policy is lower than the amount chosen by the individuals when there is a hard budget constraint. This implies that it is potentially costly for individuals to induce a bailout - in case of a bailout there will be less local public goods in their district than they are willing to pay for. Moreover, it follows that, in per-capita terms, individuals in bigger districts get smaller bailouts, making bailouts less attractive for them. In the next subsection we look in more detail at the decision whether individuals will induce a bailout. In addition, from (15) it follows that when economies of scale in local public good provision become more important, the central government is less likely to provide a bailout. Finally, it follows that the central government is more likely to provide a bailout when the spillover effect is "strong enough", and that the size of the bailout is increasing in the spillover effect.

Condition (15) makes it possible to characterize the central government's bailout policy. 
Lemma 1 There exist critical values $\overline{n_{i ; C}}, \underline{t_{i ; C}}$ and $\overline{g_{i ; C}}$ such that:

1. if $n_{i}>\overline{n_{i ; C}}$ the central government does not provide district $i$ a bailout, even when district $i$ chooses a zero level of own-contribution to local public good provision;

2. if $n_{i}<\overline{n_{i ; C}}$ the central government provides a bailout to district $i$ if and only if $t_{i}>\underline{t_{i ; C}}$ and $g_{i}<\overline{g_{i ; C}}$.

\section{Proof of Lemma 1:}

(1): From condition (15) it follows that when $g_{i}=0$ a necessary condition for $\underline{m_{i}}>0$

is $\kappa v^{\prime}(0)>\frac{n_{i} p_{i}}{N}$. Hence, for $n_{i}>\overline{n_{i ; C}}=\frac{\kappa N v^{\prime}(0)}{p_{i}}$ the central government never provides a bailout.

(2): Let $\overline{g_{i ; C}}$ be so that $\kappa v^{\prime}\left(\overline{<g_{i ; C}}\right)=n_{i} p_{i} / N$ and $\underline{t_{i ; C}}=\frac{F+n_{i} p_{i} g_{i}+c_{B O}+n_{i} p_{i} m_{i}-N \kappa v\left(g_{i}+\underline{m_{i}}\right)}{n_{i}}$. Then for $g_{i}<\overline{g_{i ; C}}$ it holds that $\kappa v^{\prime}\left(\overline{g_{i ; C}}\right)>n_{i} p_{i} / N$. If in addition $t_{i}>\underline{t_{i ; C}}$ then from condition (15) it follows that the government will provide a bailout.

Note that this bailout policy is also the policy one would obtain under majority voting, that is when individuals vote over pairwise comparisons of bailout levels. It follows from Lemma 1 that the willingness of the central government to provide bailouts and district size are negatively related. As argued above, however, the willingness of the central government to give a bailout is not sufficient for a bailout to take place. In the following section we therefore look at whether local governments indeed choose to induce such a bailout. 


\subsection{Local government bailout policy}

The central government bailout policy, implicitly given by condition (15), does not fully characterize the occurrence of bailouts. The condition shows how and when a district can induce a bailout from the center. This does not, however, imply that such a bailout is attractive for the individuals in a district. In other words, condition (15) is necessary, but not sufficient. As already mentioned in the previous section, it follows from (15) that in per-capita terms, individuals in bigger districts get smaller bailouts, thus making the choice for a bailout less attractive to them. Below we analyze this choice made by individuals, given the soft-budget constraint.

First note that, for any $g_{i}$ such that $\kappa v^{\prime}\left(g_{i}\right)<n_{i} p_{i} / N$ the district will receive no bailout at all. In this case, the optimal choice for the individuals in district $i$ therefore is $\hat{g}_{i}$. Secondly, when $g_{i}$ is such that $g_{i}<\hat{g}_{i}$ and as long as both conditions in the first line of (15) are met, it follows that the amount of local public goods provided under a bailout is not affected by the value of $g_{i}$. Individuals within the district that induces a bailout naturally are interested in making their own contribution to local public good provision as small as possible. An obvious way to do this is by choosing $g_{i}=t_{i}=0$.

It may then be the case, however, that although $\kappa v^{\prime}(0)>n_{i} p_{i} / N$ the second inequality of the first line of condition (15) does not hold and district $i$ would therefore not get a bailout when $t_{i}=0$. In that case, it can be that, although the second inequality of the first line of condition (15) does not hold for $t_{i}=0$, it holds for $t_{i}=F\left(1-\hat{m}_{i}\right) / n_{i}$. In the latter case, individuals in the district that gets a bailout minimize their own contribution by choosing $t_{i}=F\left(1-\hat{m}_{i}\right) / n_{i}$ and $g_{i}$ positive but 
infinitesimally small. We assume, however, that individuals in district $i$ can only induce bailouts with $t_{i}=0$. Note that if district $i$ gets a bailout with $t_{i}=0$ then it would also get a bailout with any $0<t_{i} \leq F\left(1-\hat{m}_{i}\right) / n_{i}$ and that the type of bailouts we focus on is thus the only type one could observe when there were no economies of scale in local public good provision.

For analytical tractability we focus in the remaining of this section on a particular class of the payoff functions $v($.$) , either v(g)=\ln (g+1)$ or $v(g)=g^{1-\alpha} /(1-\alpha)$ for $\frac{1}{2} \leq \alpha<1$. This covers a broad range of payoff functions $v($.$) that are "concave$ enough".

Individuals within district $i$ prefer to induce a bailout with $t_{i}=0$ and $T$ given by expression (9) over an optimal level of public good provision $g_{i}=\hat{g}_{i}$ when

$$
\begin{gathered}
v\left(\underline{m_{i}}\right)+\sum_{j \neq i} \kappa v\left(\hat{g}_{j}\right)+y-\left(T+\frac{F+c_{B O}+n_{i} p_{i} \underline{m_{i}}}{N}-\frac{\left(F+n_{i} p_{i} \hat{g}_{i}\right) \hat{m}_{i}}{N}\right)> \\
v\left(\hat{g}_{i}\right)+\sum_{j \neq i} \kappa v\left(\hat{g}_{j}\right)+y-\left(\frac{F}{n_{i}}+p_{i} \hat{g}_{i}\right)\left(1-\hat{m}_{i}\right)-T
\end{gathered}
$$

which, using expressions (7), (12) and (15), can be rewritten as

$$
v\left(\hat{g}_{i}\right)-v\left(\underline{m_{i}}\right)<v^{\prime}\left(\hat{g}_{i}\right) \hat{g}_{i}+\frac{\left(N-n_{i}\right)(1-\kappa) F}{N\left(n_{i}+\left(N-n_{i}\right) \kappa\right)}-\kappa v^{\prime}\left(\underline{m_{i}}\right) \underline{m_{i}}-\frac{c_{B O}}{N}
$$

Condition (16) makes it possible to characterize the local government's bailout policy.

Lemma 2 There exists critical values $\overline{n_{i ; L}}$ such that if $n_{i}<\overline{n_{i ; L}}$ and if the central government is willing to give a bailout to district $i$, then the local government of district $i$ will induce a bailout. 
Proof of Lemma 2: First note that when the central government is not willing to give a bailout, the local government will not induce a bailout since the per-capita costs of inducing would be $c_{B O} / N$.

Secondly, look at the case with $F=0$. The left-hand side of (16) then increases more when $n_{i}$ increases than the right-hand side if

$$
v^{\prime}\left(\hat{g}_{i}\right) \frac{\partial \hat{g}_{i}}{\partial n_{i}}-v^{\prime}\left(\underline{m_{i}}\right) \frac{\partial \underline{m_{i}}}{\partial n_{i}}>v^{\prime \prime}\left(\hat{g}_{i}\right) \frac{\partial \hat{g}_{i}}{\partial n_{i}} \hat{g}_{i}+v^{\prime}\left(\hat{g}_{i}\right) \frac{\partial \hat{g}_{i}}{\partial n_{i}}-\kappa v^{\prime \prime}\left(\underline{m_{i}}\right) \frac{\partial \underline{m_{i}}}{\partial n_{i}} \frac{m_{i}}{}-\kappa v^{\prime}\left(\underline{m_{i}}\right) \frac{\partial m_{i}}{\partial n_{i}}
$$

When $v(g)=\log (g+1)$ then $(17)$ can be rewritten as

$$
\frac{1}{n_{i}}-\frac{N \kappa}{n_{i}\left(n_{i}+\left(N-n_{i}\right) \kappa\right)}>p_{i}\left(\frac{1}{N}-\frac{N \kappa}{\left(n_{i}+\left(N-n_{i}\right) \kappa\right)^{2}}\right)
$$

and this inequality holds for $p_{i} \leq N / n_{i}$, and while from Lemma 1 we know that the central government only provides bailouts when $p_{i} \leq \kappa N v^{\prime}(0) / n_{i}=\kappa N / n_{i}<N / n_{i}$, it follows that inequality (17) holds for $v(g)=\ln (g+1)$.

For $v(g)=g^{1-\alpha} /(1-\alpha)$ expression (17) can be rewritten as

$$
\left(\frac{1}{\alpha}-\frac{\kappa}{\alpha}+\kappa\right)>\left(\frac{n_{i}+\left(N-n_{i}\right) \kappa}{N \kappa}\right)^{\frac{1}{\alpha}-2}
$$

and this inequality holds when $\frac{1}{2}<\alpha<1$ for possible value of $\kappa, n_{i}$ and $N$, so inequality (17) holds for $v(g)=g^{1-\alpha} /(1-\alpha)$.

This leads to three possibilities when $F=0$. Firstly, when (16) holds for all possible $n_{i}$ then bailouts always take place, and this is the case when $\overline{n_{i ; L}}=N / 2$. Secondly, when (16) does not hold for any $n_{i}$ then bailouts never take place and this 
is the case when $\overline{n_{i ; L}}=0$. Finally, when neither of these two does hold, then by the intermediate value theorem there exists an $\overline{n_{i ; L}}$ such that condition (16) holds if and only if $n_{i}<\overline{n_{i ; L}}$.

Finally, when $F \neq 0$, then the only difference is the term

$$
\frac{\left(N-n_{i}\right)(1-\kappa) F}{N\left(n_{i}+\left(N-n_{i}\right) \kappa\right)}
$$

and it is straightforward to show that this term is decreasing in $n_{i}$. This implies that a similar reasoning holds for $F \neq 0$.

It follows from Lemma 2 that individuals are more likely to induce a bailout when they are in a small district. Besides, from condition (16) it follows that when economies of scale in local public good provision are more important, local governments are more likely to induce a bailout. From Section 3.1, however, it followed that the central government is less likely to give a bailout when the economies of scale in local public goods provision are more important, that is, when $F$ is larger. It is therefore not clear how the economies of scale in local public good provision is related to the occurrence bailouts.

\section{Bailouts in equilibrium}

The analysis in Sections 3.1 and 3.2 specified the bailout policies of the central government and of the local government, respectively. In this section we argue that these bailouts can occur in a subgame-perfect Nash equilibrium. The crucial requirement 
for the bailout policy to be a subgame-perfect Nash equilibrium is that the central government does not have an incentive to change the system of matching grants to avoid bailouts. Recall that bailouts are costly from a social welfare point of view, since less public goods than the socially optimal amount are provided. A socialwelfare maximizing central government might, therefore, try to adjust the system of matching grants to avoid bailouts. The other possible adjustment is introducing a lump-sum transfer to be expended on local public goods. We show in this section (see the Appendix for technical details) that the central government does not always have an incentive to make these changes.

As in section 3.2 we look at the utility function $v(g)=g^{1-\alpha} /(1-\alpha)$. For tractability, we focus on $\alpha=1 / 2$ and at cases where there are no economies of scale in local public good provision, so $F=0$. Except district 1 with size $n_{1}$, districts are of equal size $n$. For the districts of size $n$, all cost parameters are equal to $p_{H}$ while the possible values for the cost parameter $p_{1}$ of district 1 are $p^{L}$ and $p^{H}$, with $p^{L}<p^{H}$, where $\operatorname{Prob}\left[p_{1}=p^{L}\right]=\operatorname{Prob}\left[p_{1}=p^{H}\right]=\frac{1}{2}$.

Now consider the following strategies:

1. Give each district an earmarked lump-sum transfer equal to the amount of public goods that would be socially optimal in that district if $p_{i}=p^{H}$ and a matching grant given by expression (12). When a local government induces a bailout, provide one when the conditions of Lemma 1 hold.

2. Induce a bailout when the conditions of Lemmas 1 and 2 are met, otherwise provide an amount of the public good that satisfies conditions (7). 
As argued above, there are majority voting arguments behind the strategies of the central and local governments.

Conjecture 1 The above-mentioned strategies are, under certain parameter restrictions, the unique subgame-perfect Nash equilibrium.

Note that districts with higher costs of public good provision provide less of these goods. Bailouts can thus be avoided in all districts with $p_{i}=p^{H}$ by giving these district an earmarked lump-sum transfer equal to the amount of public goods that would be socially optimal in that district if $p_{i}=p^{H}$. These transfers are earmarked in the sense that they have to be spent on local public goods. In addition to that, districts get the matching grant given by expression (12). It is straightforward to show that this leads to the socially optimal outcome.

Next to the matching grants there are earmarked lump-sum grants that depend on $p^{H}$. Lemma 1 and 2, however, are proven only for the case in which there are no lump-sum grants. To make sure we can still use the results of these lemmas, we have to show that it is not socially optimal to provide public goods in district 1 when $p_{1}=p^{H}$, and therefore no earmarked lump-sum transfer is given to district 1 . This is the case when $p^{H}$ is high enough. A more precise formulation of this can be found in the Appendix.

The second possible adjustment of the system of grants would be to change the matching grant $\hat{m}_{1}$. This changes the incentives of district 1 to induce a bailout, more specifically, an increase in the matching grant $m_{1}$ would decrease the incentives to induce a bailout. When district 1 is small enough, however, a social-welfare 
maximizing central government does not have an incentive to do this. A more precise formulation can again be found in the Appendix.

It thus follows that the central government does not have an incentive to deviate from the system of matching grants $\hat{m}$ if district 1 is small enough and $p^{H}$ is high enough. Recall that $p_{1}$ is known to the local but not to the central government. Lemmas 1 and 2 then indeed describe the subgame-perfect Nash equilibrium strategies, and bailouts take place in such an equilibrium.

Finally, note that it is important which equilibrium concept one uses. In a subgame-perfect Nash equilibrium players do not have the possibility to commit to strategies. A social-welfare maximizing government thus cannot commit not to provide bailouts, even though this would be welfare maximizing. The impossibility of such a commitment is, in our view, another typical characteristic of bailouts.

\section{Concluding remarks}

There is much evidence, in developing as well as developed countries, that relatively small districts are more likely to be bailed out. This paper focuses on the relationship between size, spillovers and soft budget constraints in a model where positive externalities in the provision of local public goods motivates grants and bailouts from the central government to districts. The analysis includes economies of scale in local public good provision and we get results that differ from previous contributions, but that are in line with the evidence. From the model four broad conclusions emerge:

[1] The willingness of the central government to bail out a subnational jurisdiction 
depends negatively on the size of the jurisdiction.

[2] The willingness of a subnational jurisdiction to induce a bailout and the size of this jurisdiction are negatively related.

[3] Bailouts can occur in a subgame-perfect Nash equilibrium. As long as the subnational jurisdiction that might get a bailout is small enough, the prevention of a potential bailout is too costly.

[4] When economies of scale in local public goods provision are more important, then local governments are more likely to induce bailouts, but the central government is less likely to give one.

\section{Appendix: Spillovers}

In this appendix we show that the main results of the paper are robust for a different specification of the spillover effect, namely that the spillover effect is increasing in the size of the district where the public good is provided.

In the main text, the spillover effect is related to the per capita amount of local public goods. When the central government considers a bailout, the costs of a bailout are increasing in district size, but the spillover effect does not. In this appendix the spillover effect is, however, increasing in the total amount of local public goods, and we argue that even in this case the main conclusions still hold.

We assume that an individual in district $i$ gets a benefit $\kappa n_{j} v\left(g_{j}\right)$ of the public

goods $g_{j}$ provided in district $j,(i \neq j)$. In a non-cooperative equilibrium the utility 
of an individual in district $i$ thus is

$$
v\left(g_{i}\right)+\sum_{j \neq i} \kappa n_{j} v\left(g_{j}\right)+y-t_{i}
$$

where $t_{i}$ is given by (2). It is straightforward to show that the non-cooperative equilibrium is again given by (4).

The socially optimal or efficient outcome is now determined by the following maximization problem

$$
\max _{g_{i}} n_{i} v\left(g_{i}\right)+\sum_{j \neq i} n_{j} \kappa n_{i} v\left(g_{i}\right)+N y-N T
$$

where $T$ is defined by (6). Let $\hat{g}_{i}$ again denote the socially optimal or efficient outcome, where $\hat{g}_{i}$ satisfies the first-order condition of this maximization problem:

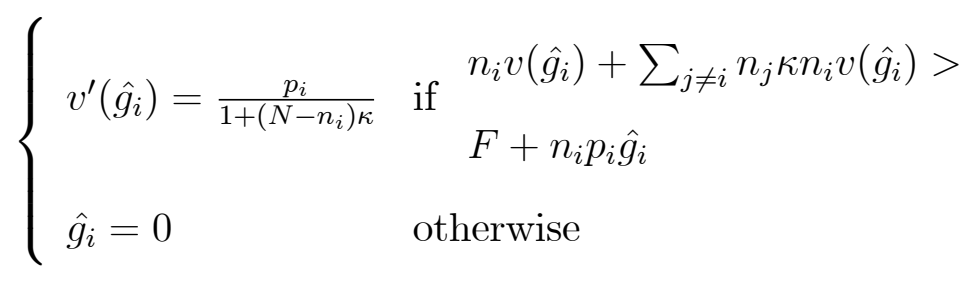

A comparison of the first-order conditions (18) with (4) yields that there is again underprovision of public goods. As in Section 2, it is possible, however, to find a system of matching grants that induces the optimal outcome. Individuals choose to provide the social efficient when the central government chooses the following matching transfers $\hat{m}_{i}$

$$
\hat{m}_{i}=\frac{N \kappa}{1+\left(N-n_{i}\right) \kappa}
$$


We now focus on soft budget constraints. As in Section 3.1, we first analyze the central government bailout policy. The central government maximizes the payoff of an individual located outside the district that might get a bailout, and this optimization problem can be written as

$$
\max _{\underline{m_{i}}} \kappa n_{i} v\left(g_{i}+\underline{m_{i}}\right)-T_{B O}
$$

where $T_{B O}$ is given by (14). The first-order condition of this maximization problem is given by

$$
\begin{cases}\kappa v^{\prime}\left(g_{i}+\underline{m_{i}}\right)=\frac{p_{i}}{N} \text { if } & \kappa v^{\prime}\left(g_{i}\right)>\frac{p_{i}}{N} \text { and } \\ & \kappa n_{i} v\left(g_{i}+\underline{m_{i}}\right)>\frac{F+n_{i} p_{i} g_{i}+c_{B O}+n_{i} p_{i} \underline{m_{i}-t_{i} n_{i}}}{N} \\ \underline{m_{i}}=0 & \text { otherwise }\end{cases}
$$

Condition (19) makes it possible to characterize the central government's bailout policy.

Lemma 3 There exist critical values $\underline{\kappa_{i ; C}}, \underline{t_{i ; C}}$ and $\overline{g_{i ; C}}$ such that:

1. if $\kappa<\overline{\kappa_{i ; C}}$ the central government does not provide district $i$ a bailout, even when district $i$ chooses a zero level of own-contribution to local public good provision;

2. if $\kappa>\overline{\kappa_{i ; C}}$ the central government provides a bailout to district $i$ if and only if $t_{i}>\underline{t_{i ; C}}$ and $g_{i}<\overline{g_{i ; C}}$. 
Proof of Lemma 3: (1): From condition (15) it follows that when $g_{i}=0 \mathrm{a}$ necessary condition for $\underline{m_{i}}>0$ is $\kappa v^{\prime}(0)>\frac{p_{i}}{N}$. Hence, for $\kappa<\underline{\kappa_{i ; C}}=\frac{p_{i}}{N v^{\prime}(0)}$ the central government never provides a bailout.

(2): Let $\overline{g_{i ; C}}$ be so that $\kappa v^{\prime}\left(\overline{g_{i ; C}}\right)=p_{i} / N$ and $t_{i ; C}=\frac{F+n_{i} p_{i} g_{i}+c_{B O}+n_{i} p_{i} m_{i}-N \kappa n_{i} v\left(g_{i}+m_{i}\right)}{n_{i}}$. Then for $g_{i}<\overline{g_{i ; C}}$ it holds that $\kappa v^{\prime}\left(\overline{g_{i ; C}}\right)>p_{i} / N$. If in addition $t_{i}>t_{i ; C}$ then the government will provide a bailout.

As in Section 3.2, we now focus on the local government's bailout policy. In the remaining of this appendix we assume that the spillover effect is important enough, that is, $\kappa$ is bigger than the inverse of the minimum district size. Individuals within district $i$ prefer to induce a bailout with $t_{i}=0$ and $T$ given by expression (6) over an optimal level of public good provision $g_{i}=\hat{g}_{i}$ when

$$
\begin{gathered}
v\left(\underline{m_{i}}\right)+\sum_{j \neq i} \kappa n_{j} v\left(\hat{g}_{j}\right)+y-\left(T+\frac{F+c_{B O}+n_{i} p_{i} \underline{m_{i}}}{N}-\frac{\left(F+n_{i} p_{i} \hat{g}_{i}\right) \hat{m}_{i}}{N}\right)> \\
v\left(\hat{g}_{i}\right)+\sum_{j \neq i} \kappa n_{j} v\left(\hat{g}_{j}\right)+y-\left(\frac{F}{n_{i}}+p_{i} \hat{g}_{i}\right)\left(1-\hat{m}_{i}\right)-T
\end{gathered}
$$

which, using expressions (7), (12) and (15), can be rewritten as

$$
\left.\left.v\left(\hat{g}_{i}\right)-v \underline{\left(m_{i}\right.}\right)<v^{\prime}\left(\hat{g}_{i}\right) \hat{g}_{i}+\frac{\left(N-n_{i}\right)\left(1-n_{i} \kappa\right) F}{N n_{i}\left(1+\left(N-n_{i}\right) \kappa\right)}-\kappa n_{i} v^{\prime} \underline{\left(m_{i}\right.}\right) \underline{m_{i}}-\frac{c_{B O}}{N}
$$

Condition (20) makes it possible to show how district size and the local government's bailout policy are related.

Lemma 4 There exists critical values $\overline{n_{i ; L}}$ such that if $n_{i}<\overline{n_{i ; L}}$ and if the central government is willing to give a bailout to district $i$, then the local government of district $i$ will induce a bailout. 
Proof of Lemma 4: First note that when the central government is not willing to give a bailout, the local government will not induce a bailout since the per-capita costs of inducing would be $c_{B O} / N$.

Secondly, look at the case with $F=0$. The left-hand side of (20) increases more when $n_{i}$ increases than the right-hand side if

$$
0>v^{\prime \prime}\left(\hat{g}_{i}\right) \frac{\partial \hat{g}_{i}}{\partial n_{i}} \hat{g}_{i}-\kappa v^{\prime}\left(\underline{m_{i}}\right) \underline{m_{i}}
$$

When $v(g)=\ln (g+1)$ then this inequality can be rewritten as

$$
\left[1+\left(N-n_{i}\right) \kappa\right]\left(N-n_{i}\right) \kappa^{2} N<p_{i}\left\{\left[1+\left(N-n_{i}\right) \kappa\right]^{2}-N \kappa\right\}
$$

and since $p_{i} \leq\left[1+\left(N-n_{i}\right) \kappa\right]$ for $g \geq 0$, a sufficient condition for this inequality to hold is that $\kappa>\frac{1}{n_{i}}$.

For $v(g)=g^{1-\alpha} /(1-\alpha)$ expression (17) can be rewritten as

$$
\left[1+\left(N-n_{i}\right) \kappa\right]^{1 / \alpha-2}<[\kappa N]^{1 / \alpha-1}
$$

and this inequality holds when $\frac{1}{2}<\alpha<1$ for values of $\kappa>\frac{1}{N}$.

This leads to three possibilities when $F=0$. Firstly, when (20) holds for all possible $n_{i}$ then bailouts always take place, and this is the case when $\overline{n_{i ; L}}=N / 2$. Secondly, when (20) does not hold for any $n_{i}$ then bailouts never take place and this is the case when $\overline{n_{i ; L}}=0$. Finally, when neither of these two does hold, then by the intermediate value theorem there exists an $\overline{n_{i ; L}}$ such that condition (20) holds if and 
only if $n_{i}<\overline{n_{i ; L}}$.

Finally, when $F \neq 0$ the only difference is the term

$$
\frac{\left(N-n_{i}\right)\left(1-n_{i} \kappa\right) F}{N n_{i}\left(1+\left(N-n_{i}\right) \kappa\right)}
$$

and since this is decreasing in $n_{i}$, a similar reasoning holds for $F \neq 0$.

\section{Appendix: Bailouts in Equilibrium}

First note that when $v(g)=2 g^{1 / 2}$, and when it is efficient to provide a positive amount of local public goods in district 1 , then this amount is given by

$$
\hat{g_{1}}=\left(\frac{n_{1}+\left(N-n_{1}\right) \kappa}{n_{1} p_{1}}\right)^{2}
$$

and if a bailout is given to district 1 than the amount of public goods is given by

$$
\underline{m_{1}}=\left(\frac{N \kappa}{n_{1} p_{1}}\right)^{2}
$$

No earmarked lump-sum grant It is socially optimal to provide no public goods in district 1 when $p_{1}=p^{H}$ if

$$
n_{1} v\left(\hat{g}_{1}\right)+\left(N-n_{1}\right) \kappa v\left(\hat{g}_{1}\right)-n_{1} p^{H} \hat{g}_{1}<0
$$

that is, if $p^{H}>2 / n_{1}$. Since a district should consist of at least one individual a 
sufficient condition is $p^{H}>2$.

No change in the matching grant The central government does not have an incentive, from the social welfare point of view, to change the matching grant to district 1 when for any matching grant $m$ the expected payoff is lower than for $\hat{m}_{1}$. There are two possible cases when the matching grant could be changed, one in which individuals in district 1 start providing public goods when $p_{1}=p^{H}$, and the other in which this is not the case. For the first case the government does not have an incentive to change the matching grant if

$$
\begin{gathered}
\left\{\operatorname{Prob}\left[p_{1}=p^{L}\right]\right\}\left\{n_{1} v(g(L, m))+\left(N-n_{1}\right) \kappa v(g(L, m))-n_{i} p^{L} g(L, m)\right\}+ \\
\left\{\operatorname{Prob}\left[p_{1}=p^{H}\right]\right\}\left\{n_{1} v(g(H, m))+\left(N-n_{1}\right) \kappa v(g(H, m))-n_{i} p^{H} g(H, m)\right\}< \\
\left\{\operatorname{Prob}\left[p_{1}=p^{L}\right]\right\}\left\{n_{1} v\left(\underline{m_{1}}\right)+\left(N-n_{1}\right) \kappa v\left(\underline{m_{1}}\right)-n_{1} p^{L} \underline{m_{1}}-c_{B O}\right\}
\end{gathered}
$$

and for the second case the government does not have an incentive to change the matching grants if

$$
\begin{gathered}
n_{1} v(g(L, m))+\left(N-n_{1}\right) \kappa v(g(L, m))-n_{1} p^{L} g(L, m)< \\
\left.n_{1} v \underline{\left(m_{1}\right.}\right)+\left(N-n_{1}\right) \kappa v\left(\underline{m_{1}}\right)-n_{1} p^{L} \underline{m_{1}}-c_{B O}
\end{gathered}
$$

where $g(L, m)$ denotes the amount of public goods individuals in district $i$ provide when the matching grants are $m$ and $p_{1}=p^{L}$.

In case the matching grant differs from $\hat{m}_{1}$, an amount of public goods is provided in district 1 that differs from the efficient one, so the net aggregate payoff from providing public goods in district 1 decreases. From the discussion on earmarked 
grants it followed that $n_{1}$ and $p^{H}$ are such that it is efficient to provide no public goods in district 1 when $p_{1}=p^{H}$. With (21) this implies that for all $g(H, m)$ the following inequalities hold

$$
\begin{gathered}
n_{1} v(g(H, m))+\left(N-n_{1}\right) \kappa v(g(H, m))-n_{i} p^{H} g(H, m) \leq \\
n_{1} v\left(\hat{g_{1}}\right)+\left(N-n_{1}\right) \kappa v\left(\hat{g_{1}}\right)-n_{1} p^{H} \hat{g}_{1}<0
\end{gathered}
$$

From this it follows that it is sufficient to look at condition (22).

With a change in matching grants the central government tries to avoid a bailout. A bailout is less attractive for individuals in district 1 when they get a higher matching grant. On the other hand, however, the more the matching grant exceeds the optimal grant $\hat{m}_{1}$, the lower the net aggregate social welfare. That is, the left-hand side of (22) is decreasing in $m$. The central government therefore tries to find the matching grant $m^{*}$ such that individuals in district 1 are indifferent between providing public goods and inducing a bailout. This $m^{*}$ is implicitly given by

$$
v\left(g\left(L, m^{*}\right)\right)-\frac{n_{1} p^{L} g\left(L, m^{*}\right)}{n_{1}}\left(1-m^{*}\right)-\frac{n_{1} p^{L} g\left(L, m^{*}\right)}{N} m^{*}=v\left(\underline{m_{1}}\right)-\frac{n_{1} p^{L} \underline{m_{1}}}{N}-\frac{c_{B O}}{N}
$$

It follows from Section 3.2 that bailouts are more attractive for individuals in smaller districts, so the smaller the district the bigger the $m^{*}$ that makes the individuals indifferent between providing public goods and inducing a bailout. The left-hand side of inequality (22) is, however, decreasing in $m$ while the right-hand side does not depend on $m$, so an increase in $m=m^{*}$ makes it more likely that this inequality is satisfied and that it is optimal not to change the system of matching grants. 
Note that when $p_{1}=p^{L}$ and $g\left(L, \hat{m}_{1}\right)=\hat{g}_{1}$, inequality (22) is not satisfied for any $c_{B O}>0$. When $m=1$, however, inequality (22) can be written as

$$
c_{B O}<(1-\kappa)^{2}\left(\frac{1}{2} N-n_{1}\right)
$$

and is thus satisfied for some $c_{B O}>0$ since, by assumption, $n_{i}<N / 2$. As argued above, a decrease in $n_{1}$ increases $m^{*}$, so it follows from the intermediate value theorem that there exists an $n^{*}$ such that when $n_{1}<n^{*}$ then the central government does not have an incentive to change the matching grant to district 1 .

\section{References}

[1] Alesina, A., Spolaore, E., 1997. On the Number and Size of Nations. The Quarterly Journal of Economics 112(4), 1027-1056.

[2] Besley, T., Coate, S., 2003. Central versus Local Provision of Public Goods: A Political Economy Analysis. Journal of Public Economics 87(12), 2611 - 2637.

[3] Bordignon, M., 2000. Problems of Soft Budget Constraints in Intergovernmental Relationships: The Case of Italy. Inter-American Development Bank, Research Network Working Papers R-398.

[4] Caplan, A.J., Cornes, R.C., Silva, E.C.D., 2000, Pure public goods and income redistribution in a federation with decentralized leadership and imperfect labor mobility. Journal of Public Economics 77, 265 - 284. 
[5] Dahlberg, M., Petterson-Lidbom, P., 2003. An Empirical Approach for Evaluating Soft Budget Constraints. Working Paper 28, Uppsala University.

[6] Dewatripont, M., Maskin, E., 1995. Credit and Efficiency in Centralized and Decentralized Economies. Review of Economic Studies 62(4), 541-555.

[7] Dillinger, W., Webb, S., 1998. Fiscal Management in Federal Democracies: Argentina and Brazil. World Bank Policy Working Paper 2121.

[8] Feidler, J., Staal, K., 2007. Centralized and Decentralized Provision of Public Goods. Mimeo, University of Bonn.

[9] Goodspeed, T., 2002, Bailouts in a Federation. International Tax and Public Finance 9(4), 409 - 421. August 2002

[10] Inman, R., 1995. How to Have a Fiscal Crisis: Lessons from Philadelphia. The American Economic Review 85 (2), 378-383.

[11] Inman, R., 2001. Transfers and Bailouts: Enforcing Local Fiscal Discipline with Lessons from US Federalism. In: Rodden,J., Eskelund, G., Litvack, J. (eds), Fiscal Descentralization and the Challenge of Hard Budget Constraints, MIT Press: Cambridge, Mass.

[12] Kornai, J., 1986. The Soft Budget Constraint. KYKLOS 29(1), 3-30.

[13] Maskin, E., 1999. Recent Theoretical Work on the Soft Budget Constraint. The American Economic Review 89 (2), 421-425. 
[14] Nicollini, J. P., Posadas, J., Sanguinetti, J., Sanguinetti, P., Tommasi, M., 2002. Decentralization, Fiscal Discipline in Sub-National Governments and the Bailout Problem: The Case of Argentina. Inter-American Development Bank, Research Network Working Papers R-467.

[15] Qian, Y., Roland, G., 1998. Federalism and the soft Budget Constraint. The American Economic Review 88 (5), 1141-1162.

[16] Rodden, J., 2003. Soft Budget Constraints and German Federalism. In: Rodden, J. (ed), Fiscal Decentralization and the Challenge of Hard Budget Constraints, MIT Press: Cambridge, Mass.

[17] Sanguinetti, P., Tommasi, M., 2004. Intergovernmental Transfers and Fiscal Behavior: Insurance versus Aggregate Discipline. Journal of International Economics $62(1), 149-170$.

[18] Seitz, H., 1999. Subnational Government Bailouts in Germany. ZEI Working Paper B20.

[19] von Hagen, J., Bordignon, M., Dahlberg, M., Grewal, B., Petterson, P., Seitz, H., 2000. Subnational Government Bailouts in OECD Countries: Four Case Studies. Inter-American Development Bank, Research Network Working Paper R-399.

[20] Wildasin, D.E., 1997. Externalities and Bailouts: Hard and Soft Budget Constraints in Intergovernmental Fiscal Relations, mimeo. Vanderbilt University. 